\title{
Process and Quality Control of Load Switch (External Circuit Breaker) for Electricity Meters
}

\author{
Zhang Baoliang $^{1,}$,, Xue Yang ${ }^{1, b}$, Zhang Penghe ${ }^{1, c}$, Xu Yinghui ${ }^{1, d}$, Yang Fuli ${ }^{2, e}$, \\ Dou Zhengzhou ${ }^{3, f}$ and Xiong Dezhi, ${ }^{4, g}$ \\ ${ }^{1}$ Institute of Measurement, China Electric Power Research Institute, Haidian District, Beijing ,100192, \\ China.
}

${ }^{2}$ Stade Grid of Chongqing Electric Power Co. Electric Power Research Institute, Chongqing, 401123, China.

\author{
${ }^{3}$ Henan XJ Metering Co.Ltd, Xuchang, 461000, China. \\ ${ }^{4}$ Metrology Center of State Grid Hunan Electric Power Company, Changsha, 410007, China. \\ azhangbaoliang@epri.sgcc.com.cn, ${ }^{b}$ xueyang3@epri.sgcc.com.cn, \\ czhangpenghe@epri.sgcc.com.cn, ${ }^{d} x u y i n g h u i @ e p r i . s g c c . c o . c n,{ }^{e}$ hcyfuli@163.com, \\ f534414471@qq.com, ${ }^{9} 404451135 @ q q . c o m$.
}

Keywords: Smart electricity meter; load switch; external circuit breaker; control

Abstract. At present, the national grid invested heavily to carry out the construction of smart grid. As a key component of smart grid construction, electricity meter is developed gradually from the traditional intelligent electric energy meter, which is an important intelligent terminal in the smart grid. The extensive use of electricity meters will make the energy saving, high efficiency and safety performance of smart grid be more fully reflected. Due to its multi functionality, especially the payment control function, the load switch (external circuit breaker) is required to be higher. This paper focuses on the technology and quality control of external circuit-breaker for electricity meters.

\section{Terms and definitions}

GB 2005-10963.1 defined as well as the following terms and definitions apply to this article.

Circuit-breaker: Under the condition of the abnormal circuit conditions, such as short circuit current, and the switching device capable of closing and carrying a certain time and the automatic breaking current, the current of the circuit is closed and broken.

Automatic opening and closing. A control signal is sent out by the master or other system to control mode, the control signal of the circuit breaker closing operation.

Control mode manual. The closing and tripping process by manually way.

Remote semiautomatic control mode. The closing process by manually, breaking through the remote control circuit breaker automatically by the way.

Remote automatic control mode. The closing and tripping process by remote control automatically by the way of circuit breaker.

Smart electricity meter technical specification for load switch requirements. Load switch : user cut electrical apparatus for breaking and restoring user load. Load switch can use the built-in or external mode, when using the built-in load switch, the maximum current electric energy meter should not exceed 60A. When using the built-in, through the operation should be arc suppression measures(hardware or software), the export circuit should have error prevention safety measures to facilitate the field test. In pass, break under the condition of the above current, the life of the load switch should not be less than 6000 times, and to be able to resist 30 times, 60 times and so on the impact of the fault current, and can not cause the explosion, from fire, can not cause harm to the human body. Voltage in electric energy meter the line is applied to the reference voltage, and the current line is passed through the 1.2 Imax under the conditions of the 10 switch off test; test after that, the electric energy meter should be able to work normally. The way of applying $70 \% \sim 120 \%$ line reference voltage, load switch should be able to work properly. 


\section{Normative references}

The following documents are essential to the reference of this document. Note dated reference documents, only note the date of the version applicable to this article. Any reference to the date of the document, the latest version (including all of the amendments) applies to this article.

GB 10963.1-2005 electrical accessories for household and similar installations with over current protection circuit breakers for first parts: circuit breakers for AC. GB/T 17626.2-2006 electromagnetic compatibility testing and measurement techniques for electrostatic discharge immunity test. GB/T 17626.4-2008 electromagnetic compatibility testing and measurement techniques for electrical fast transient burst immunity test. GB/T 17626.5-2005 electromagnetic compatibility testing and measurement techniques for surge (impact) immunity test. GB/T 20645-2006 Technical requirements of low voltage electrical apparatusspecial environmental conditions. GB/T 21706-2008 modular terminal combination. GB/T 26572-2011Limit requirements for electrical and electronic products. Q/GDW 20131364 Technical specifications of single phase intelligent electric energy meter. IEC 62055-2005 electric energy measurement and payment systems -Part 31:particularrequirements-static paymentmeters for active energy (classe1 and 2).

\section{Product design idea}

Load switch design ideas are: should be guaranteed to reach the level of similar products at home and abroad at the same time, in order to avoid the Burn table, fried table and other quality accidents, increase the anti short circuit function of the product to improve the security of customer use. In the design, must consider the requirements of relay low temperature rise, low contact resistance and short circuit resistance, the structure design of the eccentric design mechanical structure, with large current shock ability of the two contact with rubbing, improve contact adhesive resistant, strong and weak between the creepage distance must be greater than or equal to $8 \mathrm{~mm}$ in order to effectively improve the safety, the use of load switch.

\section{Production process characteristics}

The load switch is good to the use of advanced production technology, metal parts should be used in high-speed punching machine, precision mold production, with no clean production process, ensure the consistency and stability of the parts, sampling by electron beam welding, this method can effectively reduce the temperature rise, to ensure the accuracy of sampling. The sampling line end terminal and the terminal riveting, manganin spot welding, to ensure the effective strength of the sample line, ensure accurate sampling.

\section{Structural type requirements}

Size and connection mode. The external circuit breaker should be in accordance with the requirements of GB/T 21706-2008 and Q/GDW 11008-2013 in the size, the guide rail plane to the most remote distance of the operating parts should not exceed $73 \mathrm{~mm}$.

Mechanical structure. The design and structure of the circuit breaker makes it reliable to operate under normal operating conditions, without danger to the operator or the environment, and not to endanger the adjacent equipment. To verify compliance with the relevant provisions of all agencies by inspection or testing.

The metal part of the circuit breaker should adopt proper plating and coating. The metal parts should not have cracks, pitting and peeling. The surface of the plastic parts should be smooth, should not have bubbles, cracks and defects etc.. When operating a circuit breaker, the outer part which is easy to touch is made of insulating material.

Breaker operating mechanism should meet the following requirements:

A) operating parts must be flexible and reliable, with a free trip.

B) full automatic control mode should have electric operation mechanism. 
C) should make the moving contact can only be placed in the closed or open position, even if the operating part is released in a middle position is also the case.

D) the breaker has the operating handle which can be manually operated and closed, and the operating handle should be fixed and reliable.

E) a good insulation between the handle and the live parts to ensure safety.

F) in addition to opening and closing of the multi pole circuit breaker, the other all poles of the dynamic contact should be guaranteed the same time and at the same time, even when only one protection is extremely overloaded.

$\mathrm{G}$ ) if the opening and closing of the neutral pole, the opening and closing of the neutral pole should be more than the protection of the first closed, then open.

$\mathrm{H})$ if a pole is used as a neutral pole with appropriate short-circuit breaking capacity, and the circuit breaker is independent of human operation, then all the pole includes a neutral pole which can move substantially simultaneously.

I) in addition to the manual control of the circuit breaker, in order to receive the sub gate, the circuit breaker shall be automatically divided and the moving contact is in the open position the manual is not closing.

J) in switching command, should support manual switching function, and switch off after power off if re power switch should have been in the state of split gate.

K) In order to support a circuit breaker of automatic control, automatic closing parts should be fully enclosed by inner shaft, automatic. In the closing function, ensure the switch manually closing the operating handle internal contact closing state is still in the open position.

Action indicator and operator. An appropriate method for the application of a circuit breaker indicates the closure and disconnection of the contacts. Be manually closed and broken start operating parts of the contact, the operation part can be used to indicate the contact position, "|" (or "close", "ON", "red") said closed position, with "O"(or"divide","OFF","green") off position. When the circuit breaker is installed vertically, the position of the operating member is the closed position of the moving contact. The contact position indicator should be reliable. Circuit breakers should be designed so that the operator, the panel or the lid can only be fixed in the correct position to ensure that the correct indication of the contact position. If the operation indication of contact position when the operation should be located in the automatic tripping corresponding with the movable contact position. In this case, the operator should have two distinct stop positions corresponding to the contact position. The motion of the machine shall not be affected by the position of the shell or cover, and is independent of any movable part. The lid is sealed by the manufacturer as an element that cannot be moved. If the guide part is used as a button, the button should not be removed from the outside of the circuit breaker. The operating element should be fixed on the shaft reliably, and the operating element can not be removed by the tool without the aid of the tool. The operating part of the circuit breaker is not removed from the outside of the housing. To test whether the test is in accordance with the requirements by visual inspection and manual operation. In addition to circuit breaker manual control way should have a red control signal lamp, lamp switch should be set up in the front, when the control signal is $\mathrm{AC} 220 \mathrm{~V}$, indicator light, when the control level is $0 \mathrm{~V}$, the light is off, easy to identify the current state of the control level of electric energy meter.

Electric structure. Take the AC220V control signal level control unit, power supply from the control signal line, switching operation can be pulled from the phase short of electricity. Take the AC220V mode feedback signal level internal series resistor of $100 \mathrm{k} \Omega$ output single-phase circuit breaker feedback signal to take power from the line; three-phase circuit breaker feedback signal from three-phase electricity, and to ensure that in any phase phase normally feedback signal, the feedback signal is AC220V square type (allow half wave), internal tandem $100 \mathrm{k} \Omega$ resistor output.

Control signal and feedback wire diameter shall be not less than $0.3 \mathrm{~mm} 2$, the two ends of the line should be connected with the anti pressure head connected, the connection head has the function of preventing wrong connection.

Circuit breaker structure should make the circuit breaker in the normal use of the conditions of installation and wiring, the live parts are not palpable. Circuit breaker structure should make the 
circuit breaker in the normal use of the conditions of installation and wiring, the live parts are not palpable. The fixing of the gasket shall be made in the process of installing the circuit breaker. Gaskets shall be of sufficient thickness and strength, and adequate protection shall be provided at the sharp edges. The inlet of the cable and the conduit pipe shall be made of insulating material or with an insulating material sleeve or similar device, which shall be fixed and with sufficient mechanical strength. The operating part of the metal should be insulated from the live parts, and the exposed conductive parts should be covered with insulating material. This requirement does not apply to devices that connect to each of the pole pieces. The metal parts of the body should not be touched.

\section{Performance requirement}

Electrical requirements. Breaker's electrical clearance should be greater than or equal to 5.5mm; circuit breaker's climbing distance should be greater than or equal to $6.3 \mathrm{~mm}$. Circuit breaker in the power frequency withstand voltage should have enough dielectric strength and to ensure isolation, leakage current should be less than $100 \mathrm{~mA}$. Breaker should be sufficient to withstand the impact voltage, should not occur breakdown discharge. Disconnect between line contact between and connected together and neutral (when applicable), each pole and the impulse withstand voltage is connected between the other phase with very should bear $6 \mathrm{kV}$. Between the poles and the circuit breaker shall be able to withstand the shock resistance of the $8 \mathrm{kV}$ withstand voltage.

Mechanical life requirements. According to GB 10963.1-2005 test requirements, operation performance test in the main circuit is current, each operation cycle includes a closed operation and followed by a breaking operation, the operation for the remote control circuit breaker automatic and automatic control mode. Special requirements should be tested under specified environmental conditions. After the action 10000 times, the test product should not have the following phenomenon:

A) Excessive wear, the rate of change of each pole power consumption is greater than $20 \%$.

B) The position of the moving contact and the corresponding position of the indicating device are not consistent.

C) The shell is damaged to be able to be touched by the test finger.

D) Electrical or mechanical connection loose.

Electrical life expectancy. According to GB 10963.1 - 2005 in the 9 test requirements, operating performance test to the rated current in the main circuit, each operation cycle includes a switching operation and then a circuit breaker for breaking operation, semi-automatic and automatic control system used in remote control mode of operation. After the action 4000 times, the test product should not have the following phenomenon:

A) Excessive wear, the rate of change of each pole power consumption is greater than $20 \%$.

B) The position of the moving contact and the corresponding position of the indicating device are not consistent.

C) The shell is damaged to be able to be touched by the test finger.

D) Electrical or mechanical connection loose.

E) Sealing compound leakage.

Control mode requirement. Circuit breaker control using AC220V level (internal series resistor in series $100 \mathrm{k} \Omega$ output).Circuit breaker feedback using AC $220 \mathrm{~V}$ series connected to the output of $100 \mathrm{k}$ ohm resistor, when the external circuit breaker in the closing state, the feedback level is AC220V, internal series resistor of 100k output; when the external circuit breaker is in the off state, the feedback end without feedback signal (open circuit). Automatic control mode of circuit breaker control signal and action state to meet the requirements of table 1. 
Table 1 External circuit breaker status control table

\begin{tabular}{|c|c|c|c|c|c|}
\hline Order & Phase line & $\begin{array}{c}\text { Control } \\
\text { signal line }\end{array}$ & $\begin{array}{c}\text { Initial } \\
\text { state }\end{array}$ & $\begin{array}{c}\text { Post action } \\
\text { state }\end{array}$ & Remarks \\
\hline 1 & AC220V & $\uparrow$ & Break & Switch on & $\begin{array}{c}\text { (From 0V jump to AC220V) } \\
\text { received signal switch on }\end{array}$ \\
\hline 2 & AC220V & AC220V & Switch on & Break & Hand brake \\
\hline 3 & AC220V & AC220V & Break & Switch on & switch by hand \\
\hline 4 & AC220V & $\downarrow$ & Switch on & Break & $\begin{array}{c}\text { (From 0V jump to AC220V) } \\
\text { received break signal }\end{array}$ \\
\hline 5 & AC220V & $\downarrow$ & Break & Break & $\begin{array}{c}\text { (From 0V jump to AC220V) } \\
\text { received break signal }\end{array}$ \\
\hline 6 & AC220V & $0 \mathrm{~V}$ & Break & Break & $\begin{array}{c}\text { 0V control signal, do not allow } \\
\text { switch on (manual) }\end{array}$ \\
\hline 7 & $\begin{array}{c}\text { AC220V } \rightarrow \\
0 \mathrm{VC} 22 \\
0 \mathrm{~V}\end{array}$ & AC220V & Switch on & Switch on & $\begin{array}{c}\text { Do not allow the break and then } \\
\text { switch on }\end{array}$ \\
\hline 8 & $\begin{array}{c}\text { AC220V } \rightarrow \\
0 \mathrm{AC} \rightarrow \mathrm{AC}\end{array}$ & AC220V & Break & Break & $\begin{array}{c}\text { Do not allow the break and then } \\
\text { switch on }\end{array}$ \\
\hline 9 & $0 \mathrm{~V}$ & $/$ & Break & Break & $\begin{array}{c}\text { Line power down, maintain the } \\
\text { original state }\end{array}$ \\
\hline 10 & $0 \mathrm{~V}$ & $/$ & Switch on & Switch on & $\begin{array}{c}\text { Line power down, maintain the } \\
\text { original state }\end{array}$ \\
\hline
\end{tabular}

\section{Conclusion}

In recent years, with the development of micro electronic technology, electronic computer technology, modern communication technology and space technology

Speed development, the load switch technology has put forward new requirements, the development of new technology, new technology will undoubtedly play a role in promoting the development of load switching technology. The development of communication technology is of great significance to the development of load switch. On the one hand, due to the rapid development of communication technology, the application of the external circuit breaker is increased. Special structure of new materials, new molecular materials, high-performance composite materials, optoelectronic materials, magnetic materials, and the development of oxygen sensing magnetic materials, amorphous soft magnetic materials has important significance for the development of new, and will the emergence of new principle, new effect relay. The rise of new technologies will promote the development of different principles, different performance, different structures and uses. Driven by scientific and technological progress, the demand for traction and the development of sensitive and functional materials, will become the mainstream product of market development.

\section{Acknowledgements}

This work was financially supported by the State Grid Company, Project JLB (17201500227).

\section{References}

[1] Q/GDW11421-2015 Technical specification of external circuit-breaker for electricity meters.

[2] Qin Shicai, Yunqing Gao. Modern analog integrated electronics [M]. Beijing: Science Press, 2003. 